\title{
SEPARATING THE INFLUENCE OF ENVIRONMENT FROM STRESS RELAXATION EFFECTS ON DWELL FATIGUE CRACK GROWTH IN A NICKEL-BASE DISK ALLOY
}

\author{
J. Telesman, T.P. Gabb, L.J. Ghosn \\ NASA Glenn Research Center \\ Cleveland, $\mathrm{OH}, 44135$, USA
}

Keywords: Dwell crack growth, environmental damage, stress relaxation, life prediction

\begin{abstract}
Both environmental embrittlement and crack tip visco-plastic stress relaxation play a significant role in determining the dwell fatigue crack growth (DFCG) resistance of nickel-based disk superalloys. In the current study performed on the Low Solvus High Refractory (LSHR) disk alloy, the influence of these two mechanisms were separated so that the effects of each could be quantified and modeled.
\end{abstract}

Seven different microstructural variations of LSHR were produced by controlling the cooling rate and the subsequent aging and thermal exposure heat treatments. Through cyclic fatigue crack growth testing performed both in air and vacuum, it was established that four out of the seven LSHR heat treatments evaluated, possessed similar intrinsic environmental resistance to cyclic crack growth. For these four heat treatments, it was further shown that the large differences in dwell crack growth behavior which still persisted, were related to their measured stress relaxation behavior. The apparent differences in their dwell crack growth resistance were attributed to the inability of the standard linear elastic fracture mechanics (LEFM) stress intensity parameter to account for viscoplastic behavior.

Crack tip stress relaxation controls the magnitude of the remaining local tensile stresses which are directly related to the measured dwell crack growth rates. It was hypothesized that the environmentally weakened grain boundary crack tip regions fail during the dwells when their strength is exceeded by the remaining local crack tip tensile stresses. It was shown that the classical creep crack growth mechanisms such as grain boundary sliding did not contribute to crack growth, but the local visco-plastic behavior still plays a very significant role by determining the crack tip tensile stress field which controls the dwell crack growth behavior.

To account for the influence of the visco-plastic behavior on the crack tip stress field, an empirical modification to the LEFM stress intensity parameter, Kmax, was developed by incorporating into the formulation the remaining stress level concept as measured by simple stress relaxation tests. The newly proposed parameter, Ksrf, did an excellent job in correlating the dwell crack growth rates for the four heat treatments which were shown to have similar intrinsic environmental cyclic fatigue crack growth resistance.

\section{Introduction}

With the increase in the operating temperatures of the new generation of gas turbine engines, dwell crack growth of nickel based powder metallurgy (P/M) superalloys has become a lifelimiting mechanical property for turbine disk components. While considerable research has been performed over the years to develop a new generation of disk alloys and optimize their heat treatments to improve dwell crack growth behavior, the understanding and modeling of this time-dependent mechanism still needs considerable development. Modeling the complex cyclic-creepenvironment damage interaction mechanisms, which control dwell crack growth behavior, has proven difficult.

Much of the previous research has focused on identifying and characterizing the grain boundary phases thought to be responsible for the environmentally induced preferential grain boundary attack [1-3], while more recent work has also focused on the crack tip stress relaxation which occurs during prolonged dwells and is thought to decrease the crack driving force and thus influence dwell crack growth behavior [4, 5]. The microstructural parameters which influence stress relaxation behavior such as $\gamma^{\prime}$ size and volume fraction are different from those which control grain boundary environmental resistance such as carbides, borides and other grain boundary species or compositional segregation $[6,7]$. One of the unresolved issues, which detracted from many dwell crack growth behavior studies, has been the lack of separation of variables, i.e. those which influence environmental resistance from those which have an impact on stress relaxation behavior. Due to the confounding of variables, no clear understanding of the damage mechanisms has emerged and no widely accepted methodology for life prediction of dwell crack growth has been adopted by the superalloy community. Yet, while the influence of stress relaxation on the dwell crack growth behavior is becoming more accepted, the life prediction methodology which is needed to account for these changes to the fracture mechanics based crack driving force must still be developed.

The primary goal of the study was to develop an improved life prediction methodology to account for the effect that crack tip stress relaxation has on dwell crack growth. As will be described in detail in the paper, a new empirically based modification to the fracture mechanics based crack driving force was developed which achieves this goal.

To account for the stress relaxation effects, it was essential to separate the environmental embrittlement contributions to crack growth, from those caused by the visco-plastic driven changes to the crack tip stress field. This was done by performing a variety of heat treatments on a $\mathrm{P} / \mathrm{M}$ superalloy to produce a wide range of microstructures which are known to have a substantial effect on dwell crack growth behavior. Specimens consisting of these microstructures were tested by performing cyclic fatigue crack growth testing at varied frequencies, while also conducting baseline dwell crack growth tests. The rationale being that if the microstructural parameters investigated produce at least some differences in their intrinsic environmental crack growth resistance, these differences would persist if the dwell portion of the load cycle is eliminated. Thus, the time-dependent stress relaxation influences would be removed and the intrinsic environmental behavior of 
various microstructures could be quantified. Once the environmental embrittlement effects are accounted for, the remaining differences in DFCG propagation rates should be caused by the inability of the LEFM based $\Delta \mathrm{K}$ or Kmax parameters, to account for crack tip stress relaxation effects. Finally, a modification to the LEFM parameters could be developed, based on the associated stress relaxation behavior, to correct for the deficiencies in utilizing linear elastic fracture mechanics concepts in life prediction methodology when substantial visco-plastic behavior is also present.

\section{Materials and Procedure}

Blanks of the NASA-developed LSHR powder metallurgy (P/M) disk alloy were heat treated at $1171{ }^{\circ} \mathrm{C}$ for 2 hours to achieve a supersolvus microstructure with an average grain size of about ASTM 8. The composition of the alloy in weight $\%$ is $20.7 \mathrm{Co}-$ 12.3Cr-4.3W-3.5 Al-3.5 Ti-2.7Mo-1.5 Ta- $1.5 \mathrm{Nb}-0.045 \mathrm{C}-0.05 \mathrm{Zr}-$

$0.03 \mathrm{~B}-\mathrm{Bal} \mathrm{Ni}$. The cooling rate from the solutioning temperature, the aging treatments as well as any additional thermal exposure are known to significantly influence dwell crack growth properties [4]. To investigate these variables in detail, material blanks were processed by varying the thermal processing conditions. In total, seven different combinations of cooling rate/aging heat treatment/exposure were investigated as detailed in Table I. These consisted of fast cool +2 step age, $\mathrm{FC}+2 \mathrm{SA}\left(202{ }^{\circ} \mathrm{C} / \mathrm{min}+855\right.$ $\left.{ }^{\circ} \mathrm{C} / 4 \mathrm{~h}+775^{\circ} \mathrm{C} / 8 \mathrm{~h}\right)$; and slow cooled plus 2 step age, $\mathrm{SC}+2 \mathrm{SA}(72$ ${ }^{\circ} \mathrm{C} / \mathrm{min}+855^{\circ} \mathrm{C} / 4 \mathrm{~h}+775^{\circ} \mathrm{C} / 8 \mathrm{~h}$ ). In addition to these treatments, selected blanks were given additional long term thermal exposures at $815{ }^{\circ} \mathrm{C}$ for either 440 hours or 2020 hours to accentuate microstructural parameters known to affect dwell crack growth. In order to provide a contrast to the long thermal exposures, tests were also conducted on specimens which were given only a fast cool treatment without any subsequent aging or thermal exposure $(\mathrm{FC}+\mathrm{NA})$.

All crack growth testing was performed using the surface flaw, $\mathrm{Kb}$ bar specimen geometry with crack lengths measured by a computerized direct current electrical potential drop system. All tests were performed at $\mathrm{R}=0.05$ with a maximum stress of $620 \mathrm{MPa}$. In order to separate the environmental response from stress relaxation crack driving force effects, no-dwell-cyclic-only testing was performed on similarly heat treated specimens at frequencies ranging from $0.333 \mathrm{~Hz}$ all the way up to $30 \mathrm{~Hz}$. To measure the influence of the environment on cyclic crack growth, testing was conducted either in lab air or in a vacuum chamber where the pressure ranged mostly from $10^{-4}$ to $10^{-5} \mathrm{~Pa}$. Stress relaxation testing was conducted for all heat treatments investigated using $6.35 \mathrm{~mm}$ diameter cylindrical specimens machined from the equivalently heat treated blanks of the same dimensions as those used for crack growth specimens. Stress relaxation specimens were heated to $704{ }^{\circ} \mathrm{C}$ and strained to $1 \%$ total strain at a testing strain rate of $0.5 \% / \mathrm{min}$. Stress relaxation was measured as a function of time for the 100 hour duration of the tests.

\section{Results and Discussion}

\section{$\underline{\text { Microstructure and Mechanical Properties }}$}

Typical microstructures produced by the heat treatments are shown for selected conditions in Figures 1 and 2 showing metallographic sections etched in $33 \mathrm{ml} \mathrm{HCl}-33 \mathrm{ml} \mathrm{HNO}-33 \mathrm{ml} \mathrm{C}_{2} \mathrm{H}_{4} \mathrm{O}_{2}-33 \mathrm{ml}$ $\mathrm{H}_{2} \mathrm{O}-1 \mathrm{ml} \mathrm{HF}$. While the full quantitative evaluation of the microstructure is still on-going, the preliminary analysis shows the trends to be very similar to those previously established for this alloy [4]. The size of the secondary $\gamma^{\prime}$ precipitates is mostly a function of the cooling rate from the solutioning temperature and is not significantly influenced by subsequent lower temperature aging and thermal exposure steps. Typically, the size of the secondary $\gamma^{\prime}$ precipitates for the slow cool treatments is up to two times larger than for the fast cool condition. In contrast, the tertiary $\gamma^{\prime}$ size is mostly controlled by the aging treatments and subsequent exposures with the size of the precipitates increasing as a function of thermal exposure.

Table I. Seven LSHR Heat Treatments Evaluated

\begin{tabular}{|c|c|c|c|}
\hline Condition & $\begin{array}{c}\text { Cooling } \\
\text { Rate } \\
\left({ }^{\circ} \mathrm{C} / \mathrm{min}\right)\end{array}$ & $\begin{array}{c}\text { Aging } \\
\text { Treatment }\end{array}$ & $\begin{array}{c}\text { Thermal } \\
\text { Exposure }\end{array}$ \\
\hline $\mathrm{FC}+2 \mathrm{SA}$ & $202{ }^{\circ} \mathrm{C} / \mathrm{min}$ & $\begin{array}{c}855^{\circ} \mathrm{C} / 4 \mathrm{~h} \\
+775^{\circ} \mathrm{C} / 8 \mathrm{~h}\end{array}$ & None \\
\hline $\mathrm{SC}+2 \mathrm{SA}$ & $72{ }^{\circ} \mathrm{C} / \mathrm{min}$ & $\begin{array}{c}855^{\circ} \mathrm{C} / 4 \mathrm{~h} \\
+775^{\circ} \mathrm{C} / 8 \mathrm{~h}\end{array}$ & None \\
\hline $\mathrm{FC}+2 \mathrm{SA}+440 \mathrm{~h}$ & $202{ }^{\circ} \mathrm{C} / \mathrm{min}$ & $\begin{array}{c}855^{\circ} \mathrm{C} / 4 \mathrm{~h} \\
+775^{\circ} \mathrm{C} / 8 \mathrm{~h}\end{array}$ & $815^{\circ} \mathrm{C}-440 \mathrm{~h}$ \\
\hline $\mathrm{SC}+2 \mathrm{SA}+440 \mathrm{~h}$ & $72{ }^{\circ} \mathrm{C} / \mathrm{min}$ & $\begin{array}{c}855^{\circ} \mathrm{C} / 4 \mathrm{~h} \\
+775^{\circ} \mathrm{C} / 8 \mathrm{~h}\end{array}$ & $815^{\circ} \mathrm{C}-440 \mathrm{~h}$ \\
\hline $\mathrm{FC}+2 \mathrm{SA}+2020 \mathrm{~h}$ & $202{ }^{\circ} \mathrm{C} / \mathrm{min}$ & $\begin{array}{c}855^{\circ} \mathrm{C} / 4 \mathrm{~h} \\
+775^{\circ} \mathrm{C} / 8 \mathrm{~h}\end{array}$ & $815^{\circ} \mathrm{C}-2020$ \\
$\mathrm{~h}$
\end{tabular}

The tensile properties for the heat treatments evaluated are shown in Table II. The FC+2SA without exposures produced the highest yield strength, while for the comparable $\mathrm{SC}+2 \mathrm{SA}$ condition, the yield strength was approximately $80 \mathrm{MPa}$ lower. In terms of the yield strength, exposing the $\mathrm{FC}+2 \mathrm{SA}$ for $440 \mathrm{~h}$ at $815^{\circ} \mathrm{C}$ lowered the strength to be equivalent of $\mathrm{SC}+2 \mathrm{SA}$ with no exposure. For the $\mathrm{SC}+2 \mathrm{SA}$ condition, subsequent $440 \mathrm{~h}$ and $2020 \mathrm{~h}$ exposures at 815 ${ }^{\circ} \mathrm{C}$ resulted in yield strength reductions of $90 \mathrm{MPa}$ and $130 \mathrm{MPa}$ respectively. Creep testing was performed for the seven heat treatments with results shown in Table III.

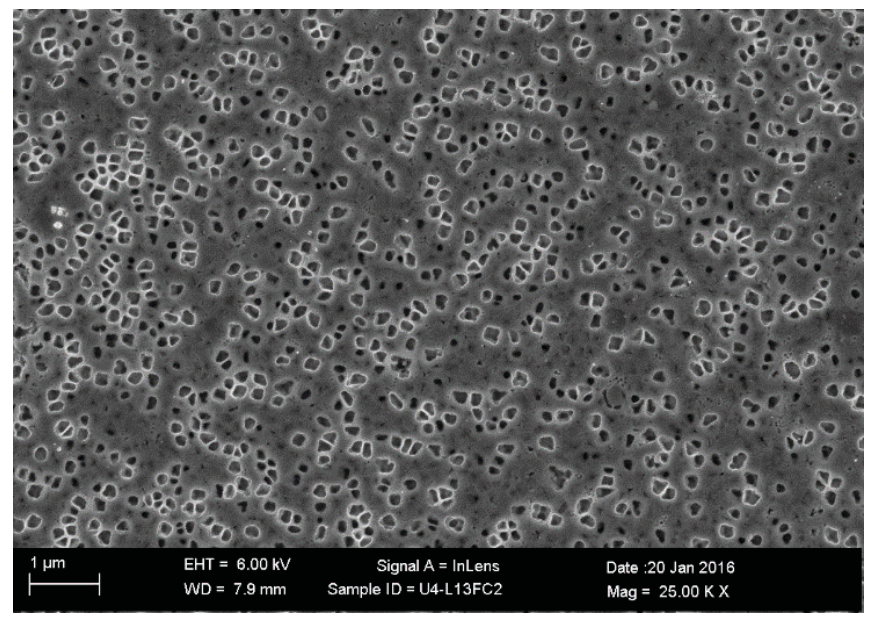

Figure 1. LSHR microstructure, $\mathrm{FC}+2 \mathrm{SA}$, no exposure. 


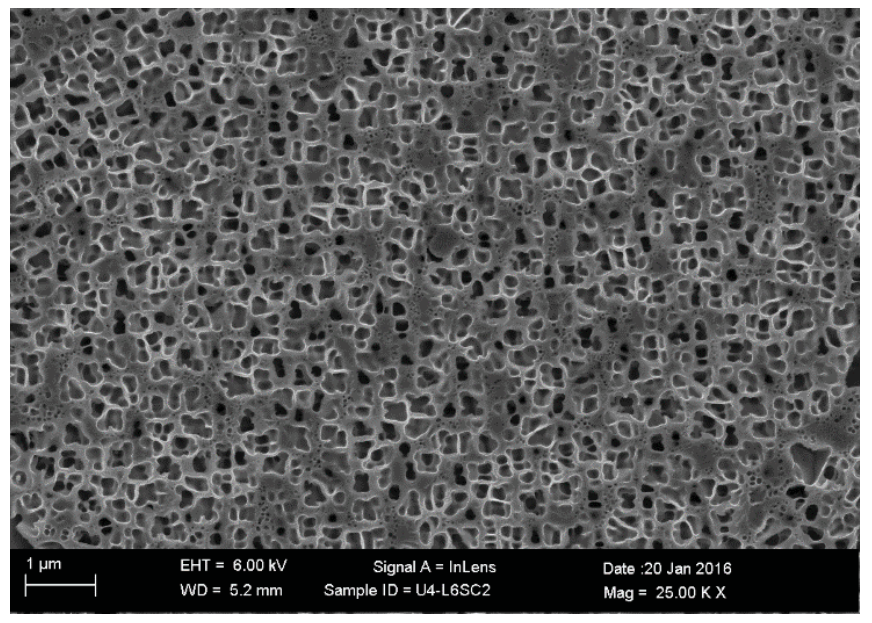

Figure 2. Microstructure, SC+2SA, no exposure condition.

Table II. Tensile Properties at $704{ }^{\circ} \mathrm{C}$.

\begin{tabular}{|c|c|c|c|c|}
\hline Condition & Exposure & $\begin{array}{c}\text { UTS } \\
(\mathrm{MPa})\end{array}$ & $\begin{array}{c}\text { YS } \\
(\mathrm{MPa})\end{array}$ & $\begin{array}{c}\text { Reduction } \\
\text { in Area - \% }\end{array}$ \\
\hline $\mathrm{SC}+2 \mathrm{SA}$ & None & 1317 & 1032 & 31 \\
\hline $\mathrm{FC}+2 \mathrm{SA}$ & None & 1386 & 1112 & 19 \\
\hline $\mathrm{SC}+2 \mathrm{SA}$ & $815^{\circ} \mathrm{C} / 440 \mathrm{~h}$ & 1355 & 942 & 36 \\
\hline $\mathrm{FC}+2 \mathrm{SA}$ & $815^{\circ} \mathrm{C} / 440 \mathrm{~h}$ & 1411 & 1032 & 27 \\
\hline $\mathrm{SC}+2 \mathrm{SA}$ & $815^{\circ} \mathrm{C} / 2020 \mathrm{~h}$ & 1314 & 898 & 34 \\
\hline $\mathrm{FC}+2 \mathrm{SA}$ & $815^{\circ} \mathrm{C} / 2020 \mathrm{~h}$ & 1382 & 1032 & 15 \\
\hline $\mathrm{FC}+\mathrm{NA}$ & None & 1447 & 1028 & 11 \\
\hline
\end{tabular}

Table III - Creep lives at $704{ }^{\circ} \mathrm{C}$ and $793 \mathrm{MPa}$

\begin{tabular}{|c|c|c|c|}
\hline Condition & $\begin{array}{c}\text { Rupture } \\
\text { (hours) }\end{array}$ & Elong. (\%) & R.A. (\%) \\
\hline $\mathrm{SC}+2 \mathrm{SA}$ & 367.4 & 11 & 15 \\
\hline $\mathrm{FC}+2 \mathrm{SA}$ & 541.4 & 2.8 & 3.8 \\
\hline $\mathrm{SC}+2 \mathrm{SA}+815^{\circ} \mathrm{C} / 440 \mathrm{~h}$ & 158.0 & 9.2 & 15.0 \\
\hline $\mathrm{FC}+2 \mathrm{SA}+815^{\circ} \mathrm{C} / 440 \mathrm{~h}$ & 191.6 & 5.0 & 5.8 \\
\hline $\mathrm{SC}+2 \mathrm{SA}+815^{\circ} \mathrm{C} / 2020 \mathrm{~h}$ & 122.0 & 8.7 & 10.1 \\
\hline $\mathrm{FC}+2 \mathrm{SA}+815^{\circ} \mathrm{C} / 2020 \mathrm{~h}$ & 173.0 & 5.5 & 5.7 \\
\hline $\mathrm{FC}+\mathrm{NA}$ & 416.0 & 1.5 & 2.7 \\
\hline
\end{tabular}

\section{Cyclic Fatigue Crack Growth Behavior}

Cyclic fatigue crack growth testing was performed in air and vacuum to determine the intrinsic environmental resistance of the different microstructures produced by the seven heat treatments investigated. The results of the cyclic fatigue crack growth tests conducted at $0.333 \mathrm{~Hz}$ and $2 \mathrm{~Hz}$ are shown in Figures 3 and 4 respectively. For both frequencies, and for all the heat treatments investigated, the tests performed in air grew considerably faster than in vacuum, with the environmental debit being substantially greater at $0.333 \mathrm{~Hz}$ tests than at $2 \mathrm{~Hz}$. At each of these test frequencies, the same four of the seven heat treat conditions, produced very similar cyclic crack growth curves. These four heat treatments were the unexposed $\mathrm{FC}+2 \mathrm{SA}$, unexposed $\mathrm{SC}+2 \mathrm{SA}$ as well as the $\mathrm{FC}+2 \mathrm{SA}$ and the $\mathrm{SC}+2 \mathrm{SA}$ exposed at $815^{\circ} \mathrm{C}$ for 440 h. At both frequencies the fastest crack growth rates were measured for the $\mathrm{FC}+2 \mathrm{SA}$ exposed at $815^{\circ} \mathrm{C}$ for $2020 \mathrm{~h}$ and the fast cool, no age condition ( $\mathrm{FC}+\mathrm{NA}$ ). The $\mathrm{SC}+2 \mathrm{SA}$ exposed at $815^{\circ} \mathrm{C}$ for 2020 $\mathrm{h}$ resulted in somewhat slower cyclic crack growth rates than the latter two conditions. The failure mode for these three conditions was predominantly intergranular while the other four conditions produced a mixed mode failure. Two examples of the observed changes in failure mode are shown in Figure 5. Thus, the results indicate that the intrinsic environmental crack growth resistance of the microstructure produced by the longest exposures or by elimination of the aging treatments is much inferior in comparison to the microstructure produced by the other heat treatments evaluated.

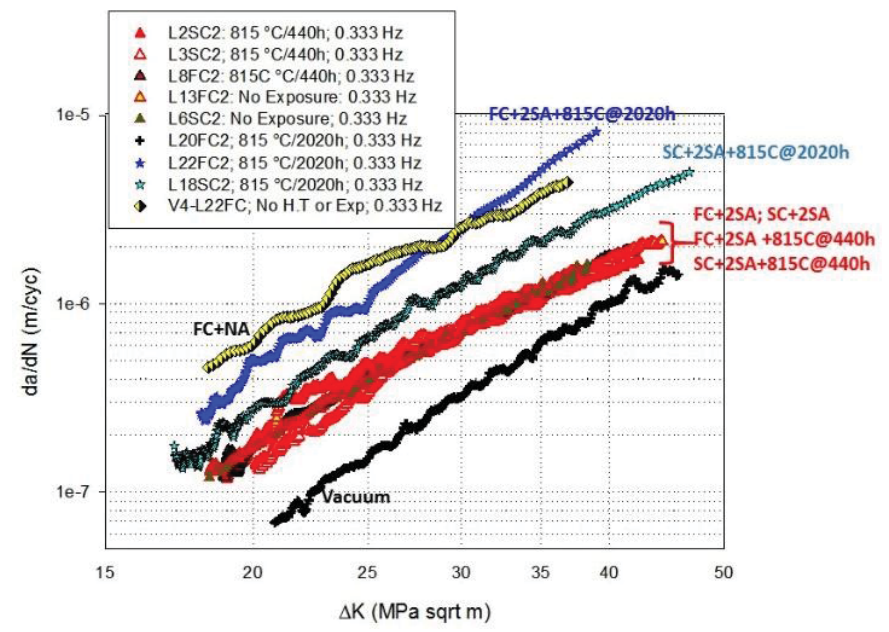

Figure 3. Cyclic FCG at $0.333 \mathrm{~Hz}$ for all seven conditions tested.

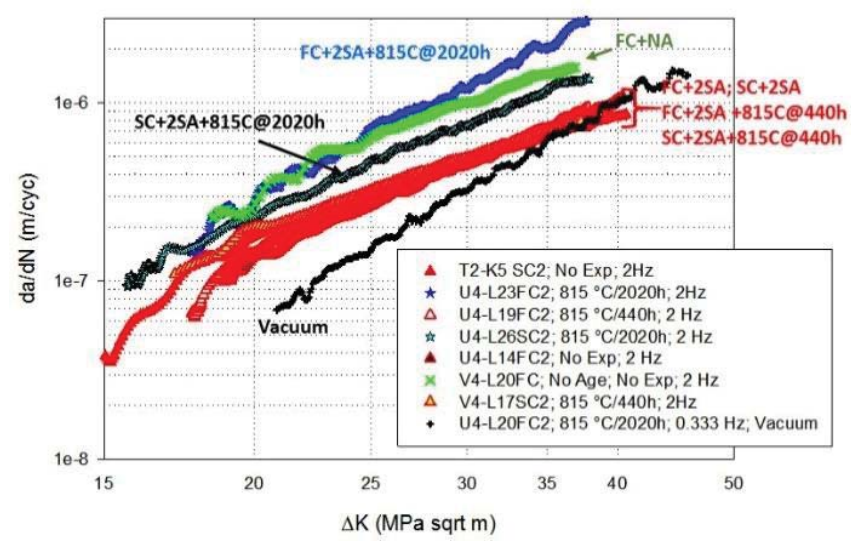

Figure 4. Cyclic FCG at $2 \mathrm{~Hz}$ at $704{ }^{\circ} \mathrm{C}$ for all conditions tested.

In order to establish if the similarities and the differences in the lab air cyclic fatigue crack growth response of these seven heat treat conditions were due to their intrinsic ability to resist environment damage, and not to other factors, vacuum crack growth tests were performed for a number of these heat treatments at varied cyclic frequencies. The results of the vacuum tests are shown in Figure 6. As shown, all the vacuum FCG curves are virtually identical irrespective of the applied heat treatment and test frequency. Thus, even the $\mathrm{FC}+2 \mathrm{SA}$ exposed at $815^{\circ} \mathrm{C}$ for $2020 \mathrm{~h}$ exhibits the same FCG response as the other heat treatments which produced much better FCG resistance when tested in air. The similarities in the 
vacuum FCG response for the heat treatments investigated indicate that the cyclic fatigue crack growth resistance is similar for all the heat treatments when environmental influence is eliminated, even though other mechanical properties are substantially different (Tables II and III). It should be noted that the crack growth data shown in Figure 6 includes the results of a 90 second dwell test conducted in vacuum for the $\mathrm{FC}+2 \mathrm{SA}$ no exposure condition. As shown in the figure, the crack growth behavior of the dwell test was very similar to all the other vacuum tests conducted. The implication of this important result will be discussed in depth later on.

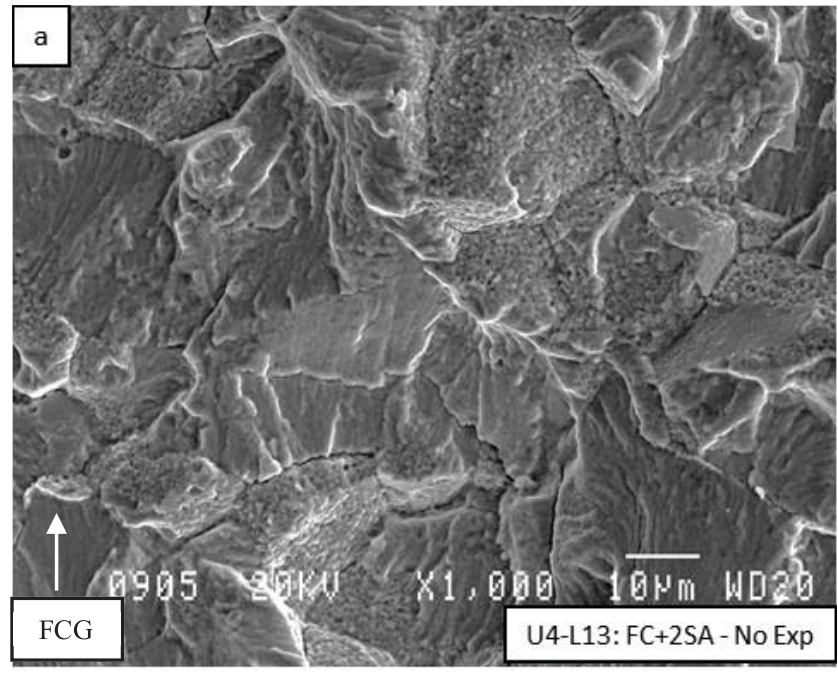

5a) $\mathrm{FC}+2 \mathrm{SA}$, no exposure tested in air at $0.333 \mathrm{~Hz}$.

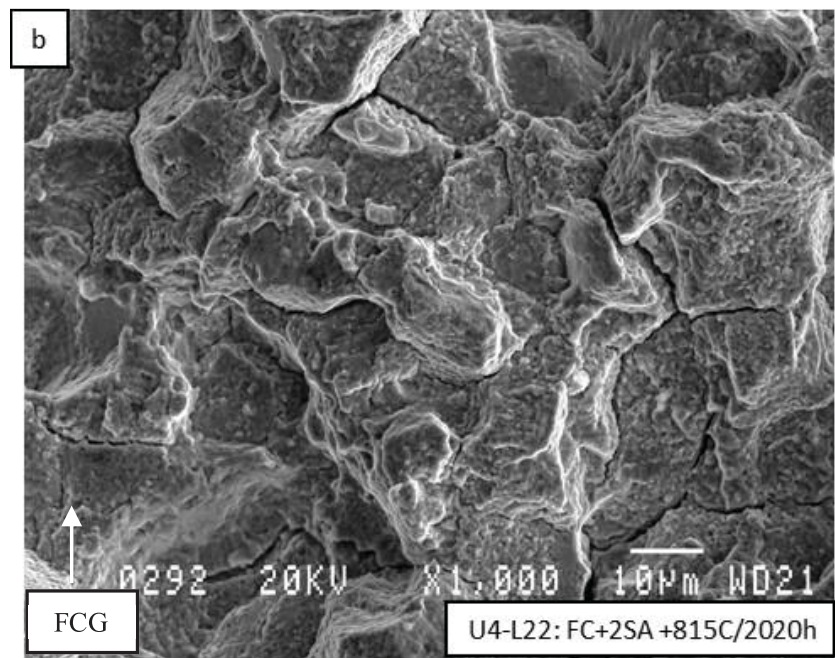

5b) $\mathrm{FC}+2 \mathrm{SA}+815^{\circ} \mathrm{C} / 2020 \mathrm{~h}$ tested in air at $0.333 \mathrm{~Hz}$

As described earlier, four of the heat treatments evaluated exhibited very similar cyclic fatigue crack growth behavior when tested in air and are thus believed to have comparable intrinsic environmental embrittlement resistance. However, these four heat treatments result in significant variations in the $\gamma^{\prime}$ precipitate structure which will be shown to significantly affect their stress relaxation behavior. Thus, these four heat treatments provide an excellent opportunity to examine the role that time dependent visco-plastic mechanisms have on dwell crack growth behavior.

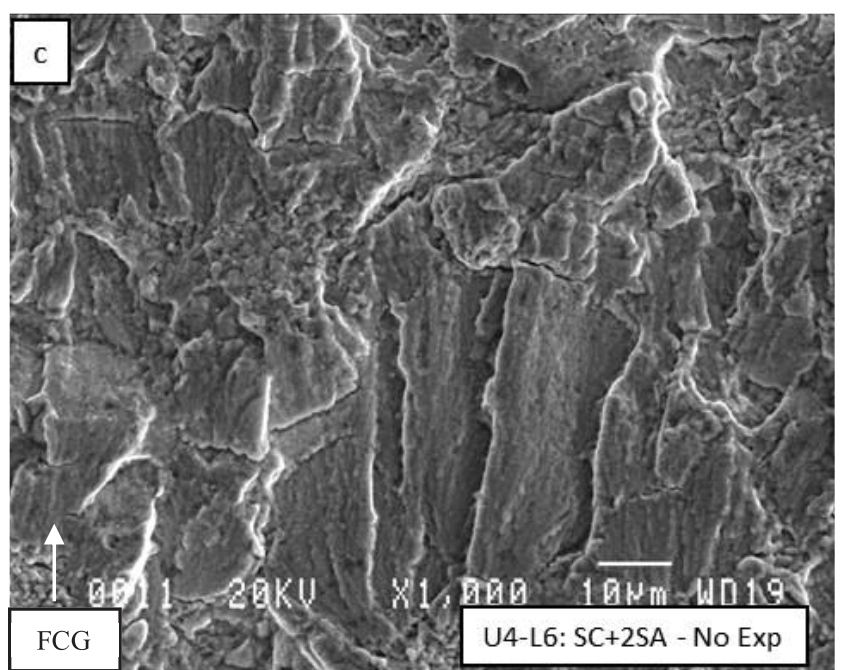

5c) SC+2SA, no exposure, tested in air at $0.333 \mathrm{~Hz}$.

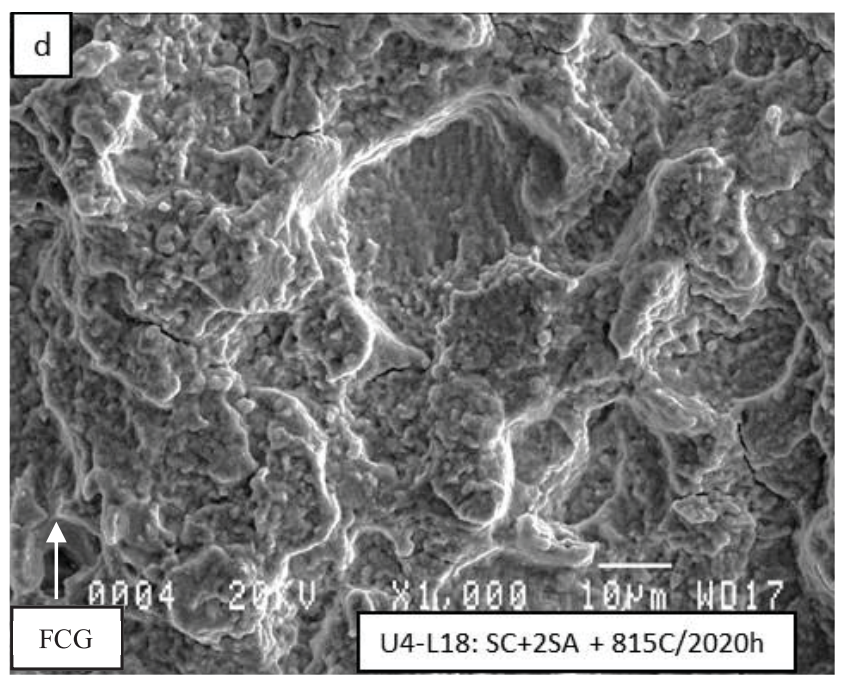

5d) $\mathrm{SC}+2 \mathrm{SA}+815^{\circ} \mathrm{C} / 2020 \mathrm{~h}$ tested in air at $0.333 \mathrm{~Hz}$.

Figure 5. Change in the failure mode due to addition of 815 ${ }^{\circ} \mathrm{C} / 2020$ h exposure.

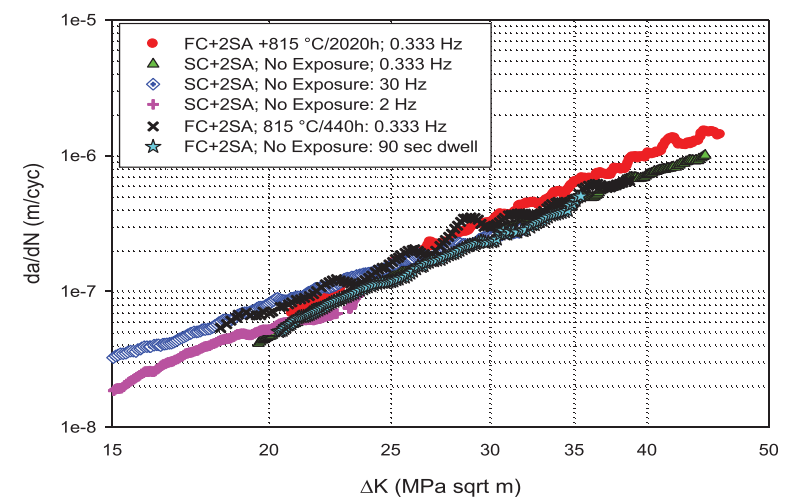

Figure $6.704{ }^{\circ} \mathrm{C}$ vacuum $\mathrm{FCG}$ behavior at various frequencies, including $90 \mathrm{sec}$ dwell, for exposed and unexposed heat treat conditions. 


\section{Dwell Fatigue Crack Growth and Stress Relaxation}

The dwell crack growth results for these four conditions are detailed in Figure 7. As shown, the trends observed for the $90 \mathrm{~s}$ dwells are comparable to those typically encountered for this class of nickel-based alloys [4]. Both the cooling rates and the thermal exposures have a significant effect on the measured dwell crack growth rates. The fastest crack growth rates are exhibited by the $\mathrm{FC}+2 \mathrm{SA}$ without exposure condition while the SC+2SA with 815 ${ }^{\circ} \mathrm{C} / 440 \mathrm{~h}$ exposure resulted in an order of magnitude slower dwell crack growth rates. Imposition of the $815^{\circ} \mathrm{C} / 440 \mathrm{~h}$ exposure resulted in approximately $3 \mathrm{x}$ reduction in time-dependent dwell crack rates $(\mathrm{da} / \mathrm{dt})$ for both fast cool and slow cool conditions. As shown in Figure 7, the addition of the $815^{\circ} \mathrm{C} / 440 \mathrm{~h}$ exposure to the $\mathrm{FC}+2 \mathrm{SA}$ condition produced dwell crack growth rates approximately equivalent to the $\mathrm{SC}+2 \mathrm{SA}$ without the additional thermal exposure. These results are consistent with other studies which correlated the improvement in dwell crack growth resistance with the imposed thermal conditions which produce an increase in the size of the strengthening secondary and tertiary $\gamma^{\prime}$ precipitates $[4,7]$.

The corresponding stress relaxation curves for these four conditions are shown in Figure 8. The data can be interpreted in terms of the remaining stress level after a given amount of time, which may be analogous to the visco-plastic driven decrease of the near crack tip tensile stresses occurring during the dwell cycles. As shown, the largest remaining stresses are for the $\mathrm{FC}+2 \mathrm{SA}$ condition with the lowest being for the $\mathrm{SC}+2 \mathrm{SA}$ exposed at $815^{\circ} \mathrm{C} / 440 \mathrm{~h}$. The two other conditions, $(\mathrm{SC}+2 \mathrm{SA}$ without exposure and $\mathrm{FC}+2 \mathrm{SA}$ with $815^{\circ} \mathrm{C} / 440 \mathrm{~h}$ exposure), show very similar stress relaxation behavior. The stress relaxation trends correspond very well to the observed dwell crack growth behavior. As shown in Figure 9, the higher the remaining stresses, the faster are the measured dwell crack growth rates. For the two conditions which showed similar level of remaining stress, the measured dwell crack growth were also similar as shown in Figures 7 and 9.

The typical interpretation of the dwell crack growth results shown in Figure 7 is to conclude that the $\mathrm{SC}+2 \mathrm{SA}$ with $440 \mathrm{~h}$ exposure produced a microstructure which is most resistant to dwell crack growth among the four conditions shown in the figure. This interpretation is contradicted by the cyclic fatigue results already presented which concluded that all four heat treatments in question have similar intrinsic environmental resistance. The imposition of the $90 \mathrm{~s}$ dwell should still lead to similar dwell crack growth response for these four conditions if their environmental resistance is also similar. Thus it is the inability of the LEFM stress intensity parameter to incorporate the crack tip stress relaxation behavior which is the real culprit leading to the apparent differences in their dwell crack growth resistance.

\section{Visco-Plastic Fracture Mechanics Based Creep Crack Growth $\underline{\text { Parameters }}$}

It has been recognized for many years that with the onset of crack tip creep deformation and the associated stress relaxation, the LEFM stress intensity $\mathrm{K}$ parameter no longer uniquely characterizes the crack tip stress field. Considerable effort has been made in the past 30 years to develop visco-plastic fracture mechanics base parameters which incorporate crack tip creep deformation into their formulation and still satisfy the requirement for uniqueness of the crack tip stress field. The two prominent parameters which have been developed are $C^{*}$ and $C(t)[8,9]$. While these parameters have been successful in describing the crack tip stress field for creep-ductile materials, they have been unsuccessful in correlating and explaining creep-fatigue crack growth in creep-brittle materials [10].

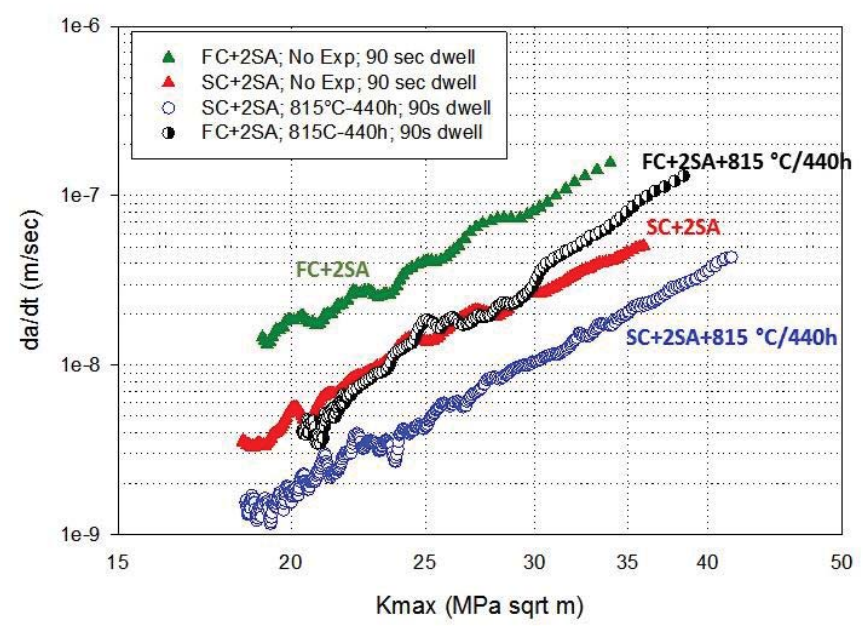

Figure 7. 90 second air dwell crack growth behavior for the four heat treat conditions thought to have similar intrinsic environmental FCG resistance.

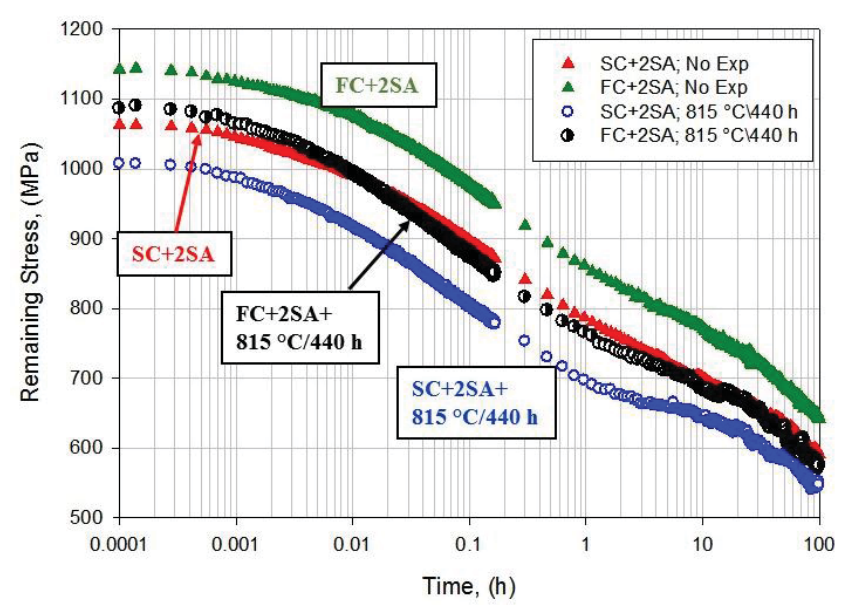

Figure $8.704{ }^{\circ} \mathrm{C}$ stress relaxation behavior for the four selected heat treatments.

Nickel-based superalloys are considered creep-brittle materials. As noted by Saxena [10] "creep-brittle materials, are those in which creep crack growth occurs in the presence of small amounts of creep deformation so the creep zone size ahead of the moving crack tip always remains constrained within a small region". Thus even for the creep-brittle materials, the underlying assumption is that time-dependent dwell crack growth occurs by classical creep mechanisms such as grain boundary sliding. However, the $90 \mathrm{~s}$ dwell crack growth test results performed in air and vacuum contradict this assumption. As was shown in Figure 6, the crack growth rates of the $90 \mathrm{~s}$ dwell specimen tested in vacuum exhibited the same fatigue crack growth rates as all the other vacuum tests performed at much higher frequencies. Thus no evidence of a creep crack growth contribution to the overall crack growth rate was detected in the vacuum tests at $704{ }^{\circ} \mathrm{C}$ in the absence of an environment conducive to crack tip embrittlement. 


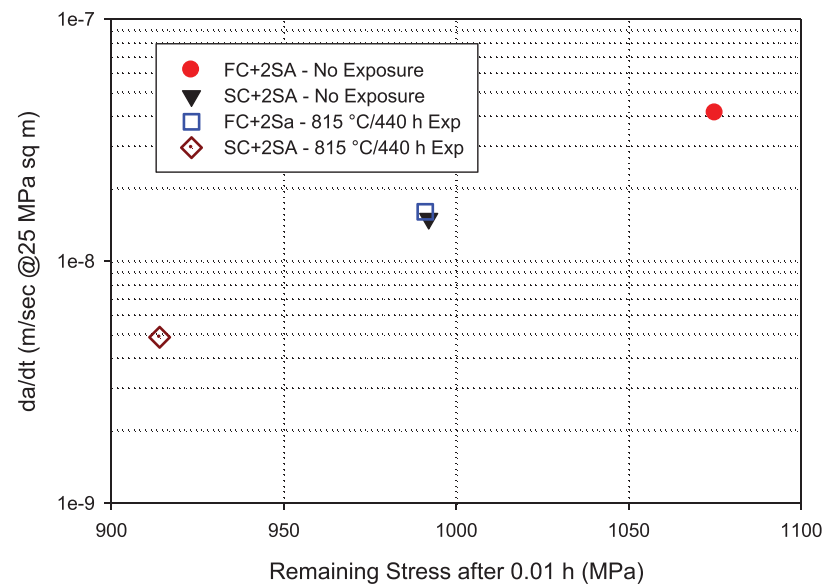

Figure 9. Relationship between stress relaxation and DFCG. Remaining stress relaxation stress at $0.01 \mathrm{~h}$ correlated to da/dt at 25 $\mathrm{MPa} \sqrt{\mathrm{m}}$

In contrast, the dwell crack growth comparison of the $90 \mathrm{~s}$ dwell tests performed in air and vacuum for specimens given the same $\mathrm{FC}+2 \mathrm{SA}$ heat treatment (Figure 10 ) reveals approximately $15 \mathrm{x}$ faster crack growth rates in air than in vacuum. Furthermore, a comparison of the two resulting fracture surfaces from these two tests indicates very different active crack growth failure mechanisms. As shown in Figure 11(a), the air-tested specimen failed through a predominantly intergranular failure mechanism. However, the vacuum test showed exclusively transgranular failure mechanisms such as striation formation from the cyclic excursions (Figure 11(b)). Even at the highest stress intensities, where creep damage is likely to be greatest, no regions of intergranular failure were observed at this temperature and applied stress.

The dwell crack growth results for these four microstructures are intriguing and at first glance appear to be contradictory. Creep and the resulting stress relaxation are closely related to the dwell crack growth resistance, as shown in Figures 8 and 9, which is also in agreement with our previous study [4]. And yet, as was demonstrated by the $90 \mathrm{~s}$ dwell vacuum test, creep crack growth itself does not contribute significantly or directly to the crack growth process (Figures. 6 and 11(b)). Thus a mechanism related to stress relaxation must influence dwell crack growth without directly being involved in advancing the crack.

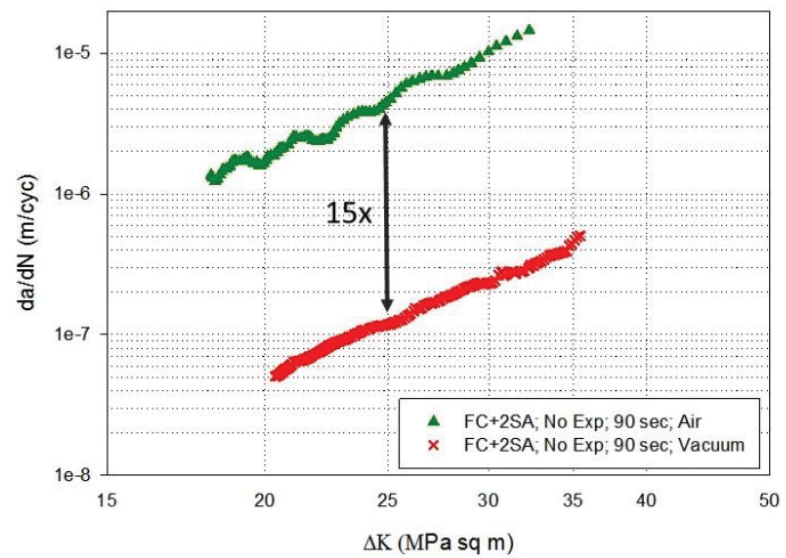

Figure 10. 15x difference between air and vacuum for $90 \mathrm{~s}$ DFCG tests at $704{ }^{\circ} \mathrm{C}$.

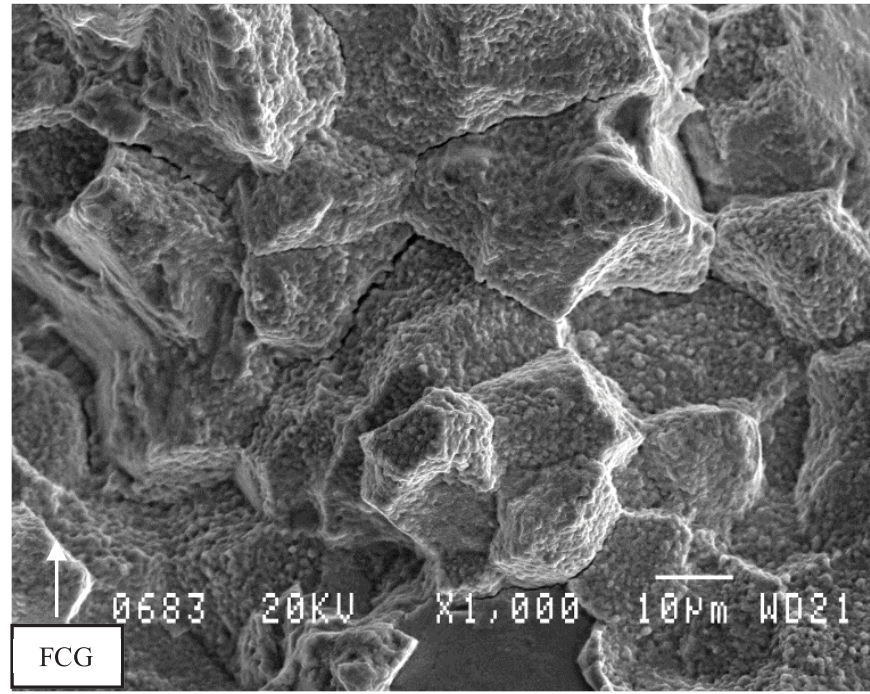

(a) $90 \mathrm{~s}$ DFCG in air at $704^{\circ} \mathrm{C}$.

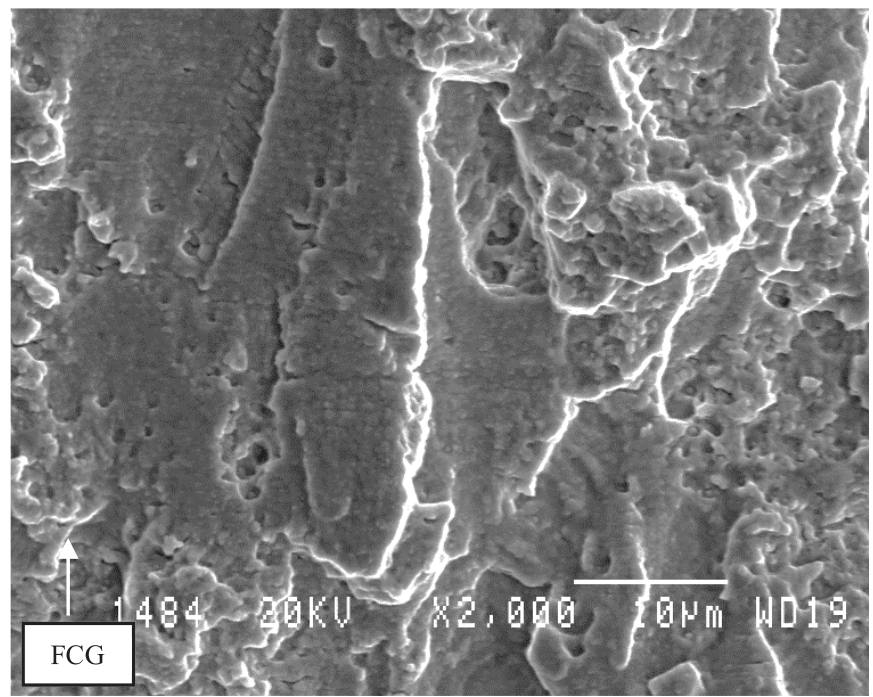

(b) $90 \mathrm{~s}$ DFCG in vacuum

Figure 11. Effect of environment on DFCG failure mode at $704{ }^{\circ} \mathrm{C}$.

\section{Visco-plastic Analysis}

To obtain a further insight into these issues, a closer evaluation of the visco-plastic crack tip stress redistribution occurring during dwell periods is required. In previous work [11], we modeled the crack tip behavior of the LSHR alloy with a slightly coarser grain size (ASTM 6) which was given three heat treatments designed also to produce considerable variation in dwell crack growth and stress relaxation. The testing was performed at $704{ }^{\circ} \mathrm{C}$ using the same specimen geometry as utilized in the current study. A visco-plastic finite element analysis (FEA) was performed to determine the magnitude of the $\mathrm{C}(\mathrm{t})$ parameter as well as evolution of the crack tip tensile stress field. The analysis was performed for a stationary crack subjected to the first ten dwell cycles. The dwell crack growth results for these three conditions as well as the evolution of the calculated visco-plastic parameter are shown in Figure 12. The $C(t)$ parameter not only was unable to correlate the dwell crack growth results, but instead produced trends completely opposite of those 
measured experimentally. Thus the heat treatment with the highest values of $\mathrm{C}(\mathrm{t})$ produced the slowest crack growth rates, while the fastest crack growth heat treatment corresponded to the lowest magnitude of the visco-plastic parameter.

These results are not that surprising since the $\mathrm{C}(\mathrm{t})$ parameter works well only for creep-ductile materials where large crack tip creep deformations take place and the creep crack growth occurs by the classical creep mechanisms such as grain boundary sliding and

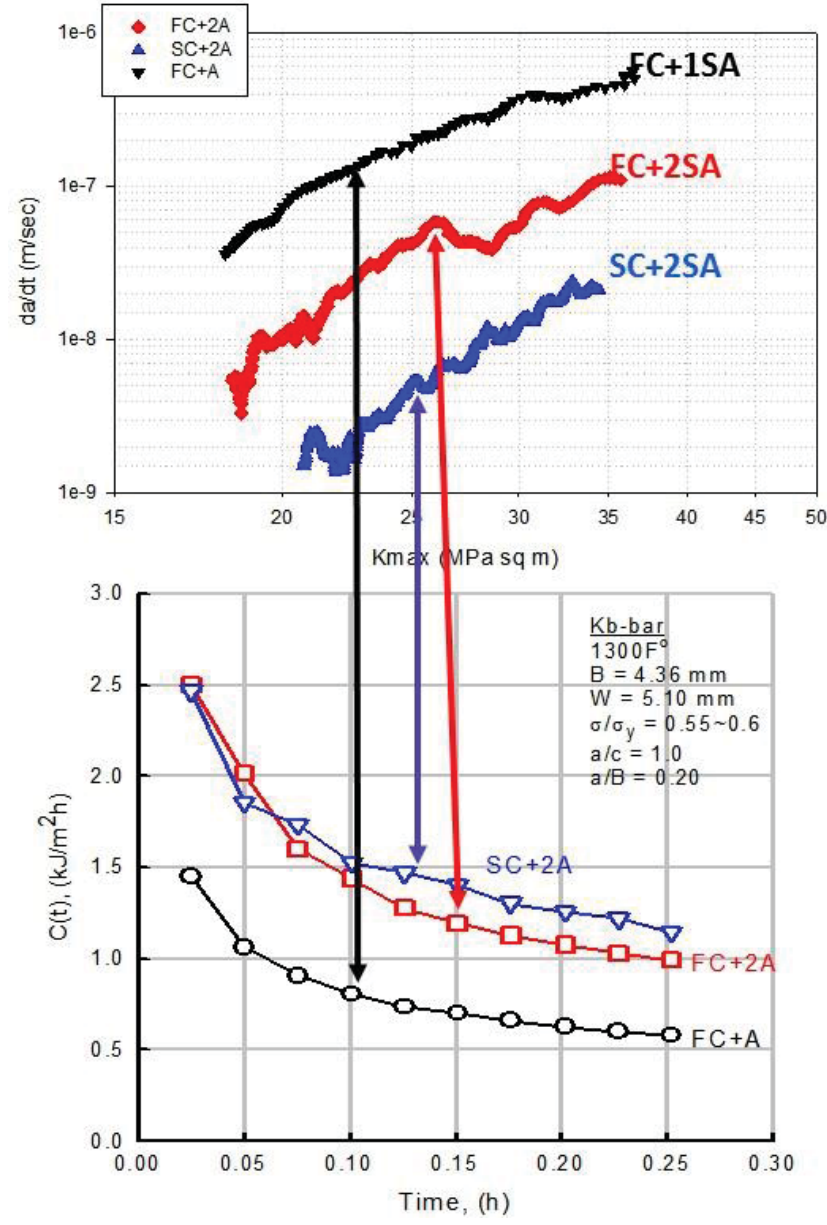

Figure 12. The $\mathrm{C}(\mathrm{t})$ parameter was unable to correlate DFCG behavior at $704{ }^{\circ} \mathrm{C}$ in a previous study of three heat treatments of large grain LSHR [11].

microvoid coalescence. However, one important outcome of this study was the calculated evolution of the tensile crack tip stresses in the loading direction as shown in Figure 13. The calculated axial crack tip stresses are in agreement with the observed dwell crack growth behavior trends. The heat treatment retaining the highest tensile stresses produced the highest crack growth rates, while the heat treatment for which the crack tip stresses are the lowest resulted in the slowest DFCG rates.

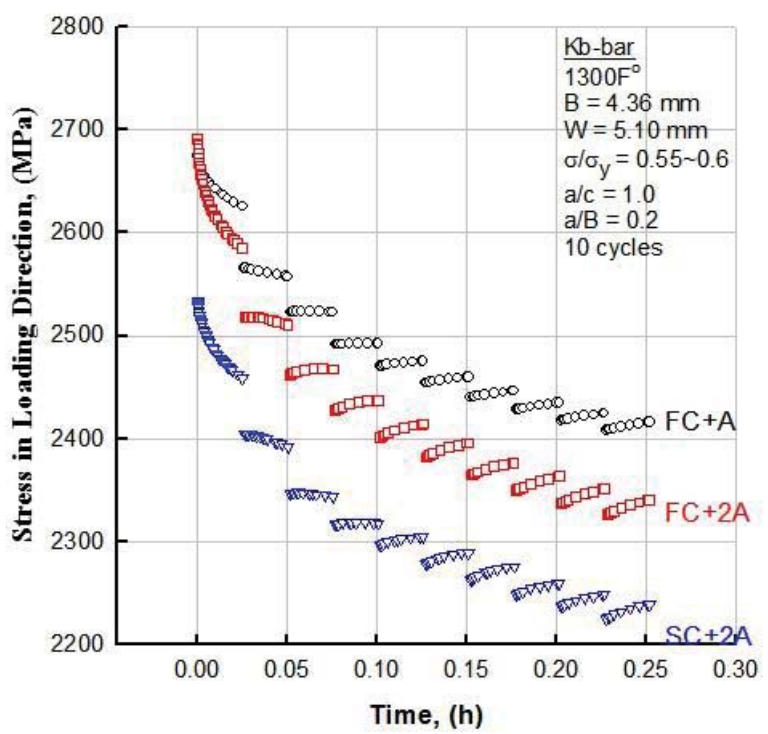

Figure 13. Visco-plastic FEA calculated near tip axial stresses were in agreement with the experimentally determined trends at $704^{\circ} \mathrm{C}$.

Since the prior work pointed to the importance of the evolution of the crack tip tensile stresses on dwell crack growth behavior, similar visco-plastic analysis was conducted for the four LSHR heat treatments used in the current study which exhibited comparable intrinsic environmental crack growth resistance. The measured stress relaxation behavior, previously shown in Figure 8, was modeled by fitting the following relationship:

$$
\dot{\varepsilon}=A \sigma^{n 1} t^{m}+B \sigma^{n 2}
$$

where $\dot{\varepsilon}$ is the strain rate, $\sigma$ is stress, $t$ is time, and $A, n 1, m, B$ and $n 2$ are fitting parameters. The parameters for each case are shown in Table IV. Visco-plastic FEA was used to calculate the magnitude of the remaining crack tip stresses for the four conditions using the above constitutive equation. Again, the analysis was done for a stationary crack and consisted of modeling the evolution of the crack tip stress field for the first ten dwell cycles.

The results are shown in Figure 14. The calculated axial crack tip stresses are mostly in agreement with the trends exhibited by the dwell crack growth results (Figure 7). The unexposed FC+2SA condition which exhibited the highest DFCG rates also exhibits the highest retained near crack tip tensile stresses, while the $\mathrm{SC}+2 \mathrm{SA}$ with $440 \mathrm{~h}$ exposure, had the lowest DFCG rates and the lowest calculated tensile stresses. For the two intermediate cases, the calculated crack tip stresses for the $\mathrm{FC}+2 \mathrm{SA}$ with $440 \mathrm{~h}$ exposure are slightly higher than for the unexposed $\mathrm{SC}+2 \mathrm{SA}$, even though the measured DFCG rates were approximately the same. This may be due to the inaccuracies in fitting the constitutive strain rate relationships constants. As shown previously in Figure 8, in the actual measured stress relaxation tests, these two conditions showed similar behavior and thus the experimental results may be a better indication of the retained stresses than the FEA analysis which is highly dependent on the ability to accurately establish the values of the fitting parameters. 


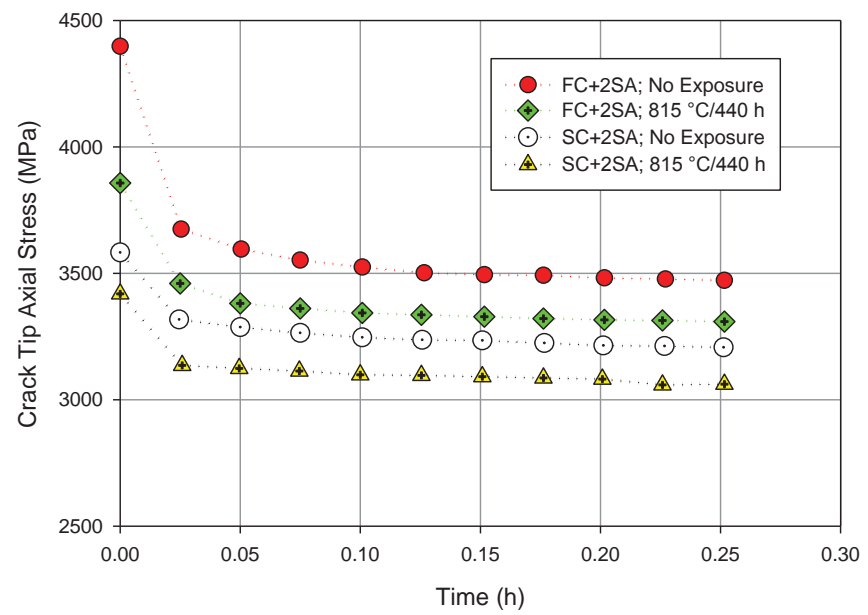

Figure 14. Visco-plastic FEA determined crack tip axial stresses for the four heat treatments investigated at $704^{\circ} \mathrm{C}$.

Table IV. Fitting Constants for Strain Rate Fit of Equation 1

\begin{tabular}{|c|c|c|c|c|c|}
\hline & $\begin{array}{c}\text { Units: time in } \\
\text { hours and stress } \\
\text { in MPa }\end{array}$ & $\begin{array}{c}\mathrm{FC}+2 \mathrm{SA} ; \mathrm{No} \\
\text { Exposure }\end{array}$ & $\begin{array}{c}\mathrm{FC}+2 \mathrm{SA}+440 / \mathrm{h} \\
\text { exposure }\end{array}$ & $\begin{array}{c}\mathrm{SC}+2 \mathrm{SA} ; \\
\text { No } \\
\text { Exposure }\end{array}$ & $\begin{array}{c}\mathrm{SC}+2 \mathrm{SA}+440 / \mathrm{h} \\
\text { exposure }\end{array}$ \\
\hline$A$ & $1 /\left(\mathrm{MPa}^{5} \cdot \mathrm{t}^{(1+\mathrm{m})}\right)$ & $5.13 \mathrm{E}-19$ & $9.63 \mathrm{E}-19$ & $7.38 \mathrm{E}-19$ & $9.63 \mathrm{E}-19$ \\
\hline$n 1$ & $\mathrm{~N} / \mathrm{A}$ & 5 & 5 & 5 & 5 \\
\hline$m$ & $\mathrm{~N} / \mathrm{A}$ & -0.77 & -0.7 & -0.8 & -0.85 \\
\hline$B$ & $1 /\left(\mathrm{MPa}^{4} \cdot \mathrm{t}^{(1+\mathrm{m})}\right)$ & $1.11 \mathrm{E}-18$ & $2.21 \mathrm{E}-18$ & $1.77 \mathrm{E}-17$ & $3.10 \mathrm{E}-17$ \\
\hline$n 2$ & $\mathrm{~N} / \mathrm{A}$ & 4 & 4 & 4 & 4 \\
\hline
\end{tabular}

\section{The Proposed Failure Mechanism}

The relationship between the remaining crack tip stress levels and the observed DFCG behavior provides an insight into the dominant mechanism governing time dependent crack growth. As was shown in a comparison between the results of the two dwell tests conducted in air and vacuum (Figure 10), the effect of the air environment overwhelms that of creep and fatigue contributions resulting in a $15 \mathrm{x}$ increase in the DFCG rates. This is accompanied by a change to a brittle intergranular failure mode (Figure 11). The air environment preferentially embrittles the crack tip region at the grain boundaries, creating very localized and substantially weakened grain boundary areas. The weakened and embrittled grain boundaries provide a preferential path for crack growth when the local tensile stresses exceed their failure strengths. The higher the magnitude of the remaining tensile stresses, the faster the crack growth process can proceed, as long as the rate of crack advancement does not exceed the diffusion driven development of environmentally embrittled grain boundaries at or ahead of the crack tip.

This scenario explains how it is possible for different microstructures to possess similar intrinsic resistance to environmental embrittlement, not exhibit any of the classical creep crack growth mechanisms and yet still be highly dependent on their visco-plastic behavior. As was demonstrated by the stress relaxation tests (Figure 8) and the visco-plastic FEA modeling (Figures 13 and 14), the remaining stress levels vary considerably based on the applied heat treatments. It is well established that the size of the secondary and tertiary $\gamma^{\prime}$ structure is a function of the cooling rates and subsequent thermal heat treatments [4]. These changes in the strengthening precipitate structure, control stress relaxation behavior and the remaining crack tip tensile stresses. The resulting crack tip stress field is a product of the applied LEFM stress intensity which has been altered by the material's viscoplastic behavior. Therefore for each microstructure, the magnitude of the crack tip tensile stress field is different since the visco-plastic behavior is controlled by the constituent microstructural parameters. It is the resulting magnitude of the crack tip tensile stresses which controls the dwell crack growth behavior through its interaction with the embrittled grain boundaries at the crack tip.

Development of a Modified Stress Intensity Parameter for Dwell $\underline{\text { Crack Growth }}$

The proposed dwell crack growth failure mechanism cannot be readily modeled using the existing damage tolerance LEFM parameters. The use of visco-plastic FEA to determine the evolution of the near crack tip tensile stress fields needed to model the dwell crack growth behavior for the various microstructures is not well developed and is also impractical for insertion into the current life prediction methodologies utilized in the aerospace industry. Thus a simplified empirical approach is needed which would accurately approximate the effect of stress relaxation on the fracture mechanics based crack driving force parameter.

An empirical modification to the LEFM stress intensity parameter, Kmax, was developed by incorporating into the formulation the remaining stress level concept as measured by simple stress relaxation tests. It is based on the assumption that the differences in the visco-plastic behavior for various microstructures, as measured by stress relaxation tests, directly correspond to the differences in the magnitude of the actual crack tip field tensile stresses. This is accomplished by normalizing the remaining stress levels measured at a given time during the stress relaxation tests and using this relationship to modify the crack driving force. The modified stress intensity parameter, Ksrf, is based on the adjustment of the LEFM stress intensity, Kmax, by a stress relaxation factor, SRF, so that:

$$
K s r f=K \max / S R F
$$

where SRF is the ratio of the measured remaining stresses, for different microstructures, at a given time during a stress relaxation test. In the case of this study, the remaining stresses after 0.01 hours were used which correspond approximately to the onset of steady state stress relaxation (Figure 8). It is defined as:

$$
S R F=\left(\sigma_{0} / \sigma_{1}\right)^{4}
$$

where $\sigma_{0}$ is a baseline remaining stress for one of the heat treatments, while the stresses for other heat treatments, such as $\sigma_{1}$, are normalized to the baseline condition. The ratio is raised to the fourth power since the calculated steady state creep strain rate stress exponent for all conditions tested was equal to four (Table IV). The dwell crack growth data for the four heat treatments which are thought to have similar resistance to environmental degradation is plotted in terms of Ksrf in Figure 15. As shown, this empirical crack driving force parameter was able to collapse all four curves within a narrow range as opposed to the factor of 10 spread in crack growth rate when correlated using a standard LEFM Kmax parameter, shown previously in Figure 7. Thus, the newly proposed Ksrf parameter was able to correlate the dwell crack growth data of four different heat treatments of LSHR, even though they possess a wide range of tensile and creep properties (Tables II and III). 


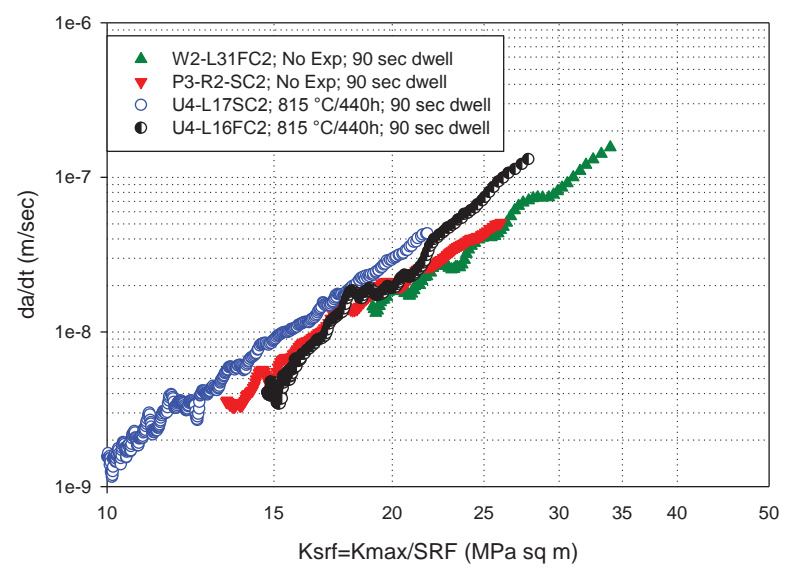

Figure 15 . DFCG at $704{ }^{\circ} \mathrm{C}$ correlated using the newly developed Ksrf parameter.

\section{$\underline{\text { Use and Limitations of the Ksrf Approach }}$}

The proper utilization and the limits of applicability of the Ksrf parameter to predict dwell crack growth need to be explained in more detail. The most important consideration is that the alloys and the heat treatments used for this type of analysis have very similar environmental resistance as measured by cyclic FCG tests. For the temperature and test conditions applied in this study, cyclic tests performed at $0.333 \mathrm{~Hz}$ were found to have the desired sensitivity to differentiate between heat treatments which were similar in their intrinsic environmental resistance versus others which contained microstructural parameters that reduced the alloy's environmental resistance. The second criteria for selection of the proper cyclic FCG frequency is that it cannot be too slow in order to prevent visco-plastic crack tip stress redistribution considerations to come into play.

The Ksrf approach is only applicable if the imposed dwells contribute to the measured crack growth rates. It is specifically designed to only measure the crack growth contribution occurring during the dwell portion of a loading cycle. In a recent internal study performed on a supersolvus Udimet 720 , crack growth testing was performed on specimens subjected to fast cool and slow cool solution heat treatments followed by conventional aging steps. It was determined that for all heat treatments the $90 \mathrm{~s}$ dwell and cyclic FCG rates were the same, thus the $90 \mathrm{~s}$ dwells did not increase the measured FCG rates. The Udimet 720 alloy has a very low creep resistance at the test temperature and thus even though the stress relaxation behavior differed substantially between the two heat treatments, the remaining crack tip tensile stress levels were too low, in both cases, to contribute to crack growth during the imposed dwells.

\section{Summary}

A study was performed to develop improved damage tolerance based life prediction methods to model dwell crack growth in a nickel-based LSHR disk alloy. Seven different microstructural variations of LSHR were produced by varying the solution heat treatment cooling rate and the subsequent aging steps and thermal exposures. Through cyclic fatigue crack growth testing performed both in air and vacuum, it was established that four out of the seven LSHR heat treatments evaluated possessed similar intrinsic environmental resistance to crack growth. For these four heat treatments, it was further shown that the large differences in dwell crack growth behavior which still persisted, were related to their measured stress relaxation behavior. It was concluded that the inability of the LEFM stress intensity parameter to incorporate the crack tip visco-plastic behavior was responsible for the apparent differences in the dwell crack growth behavior.

It was demonstrated that dwell crack growth in air was dominated by the environmental embrittlement of crack tip grain boundaries with the classical creep crack growth mechanisms having no discernible contribution to the actual crack extension. Yet, the differences in the visco-plastic stress relaxation behavior for these four microstructures had a very significant influence on dwell crack growth by controlling the remaining crack tip tensile stress field.

The magnitude of the remaining crack tip tensile stresses corresponded directly to the measured dwell crack growth rates. It was hypothesized that the environmentally weakened grain boundaries at the crack tip regions fail when their strength is exceeded by the remaining local crack tip tensile stresses. Thus microstructures with similar intrinsic cyclic environmental FCG resistance, and no discernible contribution to crack growth by classical creep crack growth mechanisms, can still exhibit large differences in their dwell crack growth behavior due to the differences in their visco-plastic stress relaxation behavior which control the tensile crack tip stress field.

An empirical modification to the LEFM stress intensity parameter, Kmax, was developed by incorporating into the formulation the remaining tensile stress level concept as measured by simple stress relaxation tests. The newly proposed parameter, Ksrf, did an excellent job in correlating the dwell crack growth data for the four heat treatments which were shown to have similar intrinsic environmental cyclic fatigue crack growth resistance.

\section{Acknowledgement}

The authors wish to acknowledge the excellent and thorough work of Mr. Andrew Ring in performing the mechanical testing. This work supports the objectives and goals of NASA's Advanced Air Transportation Technology Project funded by the Aeronautics Research Mission Directorate.

\section{References}

1. M. Gao, D.J. Dwyer and R.P. Wei, "Niobium Enrichment and Environmental Enhancement of Creep Crack Growth in NickelBase Superalloys," Scripta Met. et Mater., 32 (1995), 1169-1174.

2. K.R. Bain and R.M. Pelloux, "Effect of Environment on Creep Crack Growth in PM/HIP René-95," Metall. Trans. A, 15 (1984), 381-388.

3. L. Z. Ma, et al., "Effect of NiAl-beta Precipitates on Fatigue Crack Propagation of INCONEL alloy 783 Under TimeDependent Condition with Various Loads", Scripta Materialia, 48 (2003), 551- 557.

4. J. Telesman, et al., "Microstructural Variables Controlling TimeDependent Crack Growth in a P/M Superalloy", Superalloys 2004, ed. K.A. Green et.al., (Warrendale, PA: The Minerals, Metals and Materials Society, 2004), 215-224. 
5. K. Chan, et al., "Mitigating time-dependent crack growth in Nibase superalloy components," I. J. of Fatigue, 82 (2016), 332-341.

6. E. S. Huron et al. "The Influence of Grain Boundary Elements on Properties and Microstructures of P/M Nickel Base Superalloys," Superalloys 2004, ed. K.A. Green et al. (Warrendale, PA: The Minerals, Metals and Materials Society, 2004), 73-81.

7. K. Maciejewski and H. Ghonem, "Relative Contributions of Secondary and Tertiary $\gamma^{\prime}$ Precipitates to Intergranular Crack Growth Resistance in IN100 Alloy," Superalloys 2012, ed. E.S. Huron et al. (Warrendale, PA: The Minerals, Metals and Materials Society, 2012), 421-430.

8. J.D. Landes, J.A Begley, "A Fracture Mechanics Approach to Creep Crack Growth," in: Mechanics of crack growth, ASTM STP 590, ed. J.R. Rice and P.C. Paris (Philadelphia, PA: American Society for Testing and Materials, 1976), 128-148.

9. J. Bassani, F. McClintock, "Creep Relaxation of Stress Around a Crack Tip,” Int. J. Solids Struct., 17 (1981), 79-89.

10. A. Saxena, "Creep and Creep-fatigue Crack Growth," I.J. of Fracture, 191 (2015), 31-51.

11. J. Telesman et al., "Influence of Stress Relaxation on CreepFatigue Behavior in Nickel-based Superalloys," presented at International Symposium on Creep-Fatigue Interactions, San Antonio, TX, Nov. 2010. 